Published in final edited form as:

J Econ Educ. 2015 ; 46(1): 83-104. doi:10.1080/00220485.2014.980528.

\title{
Is it all worth it? The experiences of new PhDs on the job market, 2007-10
}

\author{
Brooke Helppie McFall, PhD ${ }^{i}$ [Assistant Research Scientist], \\ Survey Research Center, Institute for Social Research, University of Michigan, 426 Thompson \\ Street, Ann Arbor, Ml 48104, 734-764-4572 \\ Marta Murray-Close, PhD [Assistant Professor], \\ Department of Economics, University of Massachusetts, Amherst, 1018 Thompson Hall, (413) \\ 545-3412
}

Robert J Willis, PhD [Professor of Economics and Research Professor], and

Survey Research Center, Institute for Social Research, University of Michigan, 426 Thompson

Street, Ann Arbor, MI 48104

Uniko Chen, PhD [Associate Mercer]

1255 23rd St NW, Suite 500, Washington, DC 20037, 734-757-0001

Brooke Helppie McFall: bhelppie@umich.edu; Marta Murray-Close: martam@econs.umass.edu; Robert J Willis: rjwillis@umich.edu; Uniko Chen: unikochen@gmail.com

\begin{abstract}
This paper describes the job market experiences of new $\mathrm{PhD}$ economists, 2007-10. Using information from $\mathrm{PhD}$ programs' job candidate websites and original surveys, the authors present information about job candidates' characteristics, preferences and expectations; how job candidates fared at each stage of the market; and predictors of outcomes at each stage. Some information presented in this paper updates findings of prior studies. However, design features of the data used in this paper may result in more generalizable findings. This paper is unique in comparing pre-market expectations and preferences with post-market outcomes on the new $\mathrm{PhD}$ job market. It shows that outcomes tend to align with pre-market preferences, and candidates' expectations are somewhat predictive of their outcomes. Several analyses also shed light on subgroup differences.
\end{abstract}

\section{Keywords}

economics $\mathrm{PhD}$; job market; salary; preferences

The new PhD job market in economics is of great interest to both job candidates and hiring institutions. Both sides of the market naturally seek information about what they can expect. In this paper, we present findings from an original study, the Job Seekers' Project, which uses information found on $\mathrm{PhD}$ programs' job candidate websites as well as longitudinal data from original surveys. Data from this project allow us to provide hard numbers

${ }^{\mathrm{i}} \mathrm{McFall}$ is the corresponding author. 
describing the characteristics, preferences and experiences of job seekers who were on the "new PhD" job market in economics between 2007 and 2010. In particular, we examine interactions between job seekers and potential hiring institutions at each stage of the job market, job seekers' outcomes and success rates at each stage of the market, and which factors - including some that are unobservable to researchers, hiring and dissertation committees - are predictive of outcomes on the job market.

Formal studies of the new $\mathrm{PhD}$ job market in economics have illuminated several aspects of the job-market experience. A number of studies have described the employment outcomes of recent job-market participants and identified characteristics of the job candidates that predict successful job outcomes (Carson and Navarro 1988; Barbezat 1992; Siegfried and Stock 1999; Duncan et al. 2000; List 2000; Stock et al. 2000; Stock and Alston 2000; Siegfried and Stock 2004; Hilmer and Hilmer 2007; Holmes and Colander 2007). As in our study, some have also incorporated information about outcomes during the job market, including experiences with applications, interviews, fly-outs, and job offers (Carson and Navarro 1988; Duncan et al. 2000; List 2000; Stock et al. 2000; Stock and Alston 2000; Ehrenberg 2004; Deck et al. 2011). Finally, at least one study has examined the preferences of job candidates with respect to different employment outcomes and the association between preferences and outcomes (Barbezat 1992).This paper extends research on the new PhD job market in economics in several ways.

First, we use original data from a representative sample of new entrants to the job market to provide the first summary of outcomes during the job market, including outcomes related to applications, interviews, fly-outs, and job offers. Unlike prior studies, information about the various stages of the market were asked close to real-time, with questions about applications asked prior to the interview stage for many individuals. One finding derived from examining outcomes during the market is that, as the job market progresses, factors that are easily measured using information from $\mathrm{CVs}$ and other publicly-posted information begin to matter less, while factors that are unobservable based on such information begin to matter more. That is, once candidates make it through early screening, subjective factors take on more weight.

Second, we provide comprehensive information about the job-market experiences and outcomes of job candidates in three relatively recent job-market cohorts, 2007-08, 2008-09, and 2009-10. Prior studies characterize the job-market experiences of job candidates through the 2001-02 job-market cohort (Siegfried and Stock 2004); this study characterizes the experiences of job candidates in the 2007-10 job-market cohorts using a slightly different, but largely comparable sample. Siegfried and Stock's findings are largely consistent with our own, or match up well after adjustment by historical trends, such as increasing proportions of female and international $\mathrm{PhD}$ students, or inflation-adjusting earnings.

Our results from examinations of outcomes during and at the end of the job market suggest that, in addition to the fact that most candidates do receive a job offer of their preferred type by the end of the market, outcomes are also good in terms of satisfaction ratings and salary. We see no evidence that women do worse than men on most measures, but candidates who 
completed their undergraduate educations in Asia and those from lower-ranked $\mathrm{PhD}$ programs do worse on a variety of measures.

Finally, we exploit the structured timing of the new $\mathrm{PhD}$ job market in economics to assess the preferences and expectations of job candidates before they know what their job placements will be. We find that job market candidates' preferences are predictive of job type, and that pre-market expectations of job prestige are predictive of accepted job prestige.

\section{Data}

The primary job market for new economists in the United States unfolds in stages around the annual meetings of the Allied Social Science Associations (ASSA). ${ }^{\text {ii }}$ Each year, in the months leading up to the meetings, hundreds of recent and soon-to-be graduates of doctoral programs in North America and Europe submit thousands of applications for jobs throughout the world. In early January, job candidates and employers travel to the meetings to complete first-round job interviews, and in the months following the meetings, job candidates travel to prospective job sites to complete second-round interviews and to give presentations of their research. Within months of the meetings, most employers have extended job offers and most job candidates have accepted an offer or made alternate plans for the following year (Siegfried and Stock 1999, 2004). Because a majority of graduates from the most prestigious doctoral programs participate in the job market organized around the ASSA meetings, many hiring institutions that do not interview at the meetings also conform to this schedule.

The standardized timing of the new $\mathrm{PhD}$ job market in economics, together with the nearly universal practice of job candidates posting their contact information and CVs on publicly accessible job-placement websites, presents an opportunity to study the job searches of new economists as they unfold. To leverage this opportunity, the data collection procedures for the Job Seekers' Project parallel the timeline of the job market. This project, a joint effort by Brooke Helppie McFall, Marta Murray-Close, and Robert J. Willis, aims to gather data about many aspects of job candidates, including their preferences, CV content, job market experiences, job outcomes, and what happens to individuals in this sample over time. Results presented in this paper use only data from publicly-posted information and surveys from the job market year.

The sample frame for this paper comprises job candidates whose names and contact information appeared on the job-placement websites of their graduate departments between 2007-08 and 2009-10. In 2007-08 and 2008-09, it included job candidates from graduate departments in the United States and Canada whose departments were listed on the $J o b$ Candidates website of the National Bureau of Economic Research (NBER). iii The vast majority of these departments are in economics, but the list also includes some business schools, agricultural economics departments, and other closely related fields whose $\mathrm{PhD}$ recipients frequently participate in the job market for economists. In 2009-10, we expanded

\footnotetext{
ii The structure of the market is described in detail in annual job market guides by John Cawley (see, for example, Cawley 2014).

iii The Job Candidates website of the National Bureau of Economic Research is accessible at http://www.nber.org/candidates/.
} 
our sample frame to include several graduate departments in Europe, as well as several departments in the United States and Canada whose departments were not listed on the website of the NBER, increasing the number of institutions from 105 in 2007-08 to 134 in 2009-10. There were 880 job candidates in our 2007-08 list, 892 in our 2008-09 list, and 984 in our 2009-10 list. We believe that the Job Seekers' sample comprises nearly the universe of job candidates who expected to participate in the primary job market for new economists in 2008, 2009 and 2010. ${ }^{\text {iv }}$ Unless otherwise noted, regression results presented in this paper are substantively robust to exclusion of job candidates from institutions outside the United States. ${ }^{\mathrm{V}}$ Where qualitative or interesting quantitative differences occur, we document these in endnotes.

In late November and early December, as job candidates submitted their applications, the project compiled a sample list, plus posted contact, CV and supplementary information about each individual on the list, from the job-placements websites. We used the information from the websites and CVs to code a number of background characteristics of the job candidates, including program rank, ${ }^{\text {vi }}$ gender, ${ }^{\text {vii }}$ country of undergraduate education, research fields, ${ }^{\text {viii }}$ research productivity, and teaching experience. The contact information was used to invite candidates to surveys.

In late December, just before job candidates traveled to their first-round interviews at the ASSA meetings, the project sent invitations for the "pre-market" survey. The pre-market survey gathered information about demographic characteristics, pre-market preferences, and decisions during the application stage of their job search. A particularly unique feature of the 2009-10 survey was a question asking respondents how prestigious ("impressive") they expected their job market outcome to be. Most job candidates in 2007-2010 who completed the pre-market survey submitted responses before the meetings, and a vast majority ( 88 percent) submitted responses within one month of receiving the invitation to participate.

Finally, in late summer or fall, as job candidates prepared for or settled into their new jobs, the project sent invitations for the "post-market" survey. ${ }^{\text {ix }}$ The post-market surveys gathered information about the application, interview, fly-out, offer and job acceptance stages of the market, as well as detailed information about accepted jobs, including satisfaction and compensation.

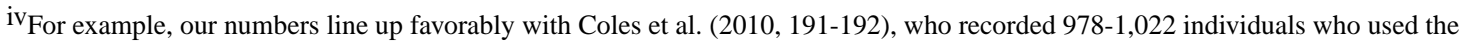
AEA signaling mechanism between 2007 and 2009. Their surveys show that about 2/3 of current PhD students on the job market (similar to the sample frame in this paper) reported signaling, and that about $2 / 3$ of those who signaled were students. Thus, if about 1,000 per year signaled, then 667 were students. These 667 were approximately $2 / 3$ of the number on the market, so the total market is around 1,000 .

${ }^{\mathrm{V} E x c l u d i n g}$ non-US institutions holds the sample size virtually unchanged from cohort-to-cohort. Sample sizes are 832 in 2007-08, 845 in 2008-09, and 826 in 2009-10. Excluding "unranked" institutions makes the samples yet more similar. Throughout the paper, we report results using all possible data.

viprogram rank comes from the U.S. News and World Report (2009) rankings of graduate programs in economics.

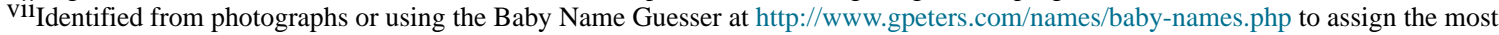
likely gender based on first name.

viii Research fields are hand-coded into 28 categories. The greatest number of fields coded for any one candidate was eight. Ninety-one percent of candidates have four or fewer fields.

${ }^{1 x}$ The 2007-08 and 2009-10 post market surveys were fielded beginning in August. The project sent invitations for the 2008-09 postmarket survey in November rather than August.
} 


\section{Sample selectivity and weighting}

Between 2007-08 and 2009-10, the response rate for the pre-market survey was 53 percent, and the response rate for the post-market survey was 39 percent. Response rates for the Job Seekers surveys are comparable or superior to the response rate for a typical web survey (Cook et al. 2000), and that reported for the graduate survey by Siegfried and Stock (2004). However, sample selectivity is still a concern, as it may bias estimates in our analyses. A unique strength of this project is that our combination of data from web surveys and publicly-accessible websites allows us to create weights to adjust for sample selectivity. Using information available for both respondents and non-respondents from the CV and placement website data, ${ }^{\mathrm{X}}$ we created smoothed, regression-based propensity weights to adjust for non-response. We created three different sets of weights for this paper: one set of weights for analyses that use only pre-market survey data (referred to hereafter as "premarket weights"), one set for those that use only post-market survey data ("post-market weights"), and one set for those that use data from both survey waves ("two-wave weights"). Based on comparisons of the raw inverse probability weights with the smoothed weights and goodness-of-fit tests, there is no evidence that our weights are misspecified. Aided by our weights, we believe that our results are generalizable to nearly the universe of job candidates who expected to participate in first-round job interviews at the ASSA meetings in 2008, 2009 and 2010.

\section{Results}

\section{Characteristics of job candidates}

Table 1 presents means and standard errors of key demographic, educational, and professional variables coded from the websites and CVs. The statistics are calculated using data from all of the job candidates in the 2007-10 Job Seekers sample for whom we obtained complete background information, whether or not they responded to the surveys.

Just under one third of job candidates in the sample were women, a slight increase since 2001, when just twenty-eight percent of PhDs in economics in the United States were awarded to women (Siegfried and Stock 2004). Approximately one third had obtained their undergraduate education in each of the three locations we coded: the United States, countries in Asia, and countries elsewhere in the world. ${ }^{x i}$ More than nine in ten job candidates had obtained their doctoral training in the United States, and an equally large majority had obtained their training from departments of economics. ${ }^{x i i}$

The distribution of job candidates across graduate departments indicates that job-market participants come disproportionately from highly ranked departments. This is not surprising,

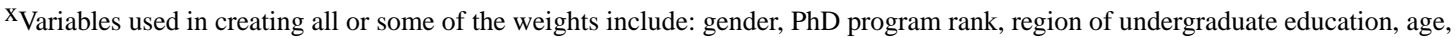
additional degrees, teaching experience, number of journal publications, undergraduate field, whether CV was posted on website, country of PhD institution, field, and citizenship.

${ }^{\mathrm{Xi}}$ Results from the surveys indicate that location of undergraduate institution is a good proxy for citizenship. We identify Asian countries following the classification scheme of the Population Reference Bureau (2008).

xii The only qualitative difference when we exclude non-US PhDs is that a greater proportion of the US PhD sample is from US undergraduate institutions, and slightly more in each ranking level of institutions. The latter is mechanical, since rankings are based on US programs only, and the former is intuitive. Other than these differences, all estimates are within one percentage point of those presented in the table.
} 
since these tend to be larger programs. More than one quarter of the job candidates in the Job Seekers sample had obtained their doctoral training from economics departments ranked in the top ten by U.S. News and World Report (2009). Another quarter had obtained their training from departments ranked between 11 and 30, while less than one fifth had obtained their training from departments ranked between 41 and 50 . xiii

Information from the CVs suggests that job candidates are more likely to enter the job market with teaching experience than a publication record. On average, a job candidate in the Job Seekers sample had served as a teaching assistant for more than three courses and had served as a primary instructor for between one and two courses. In contrast, just 28 percent of job candidates had published an article in a journal by the time they entered the job market, and most of those who had published an article had published only one.

Job candidates listed a wide range of fields on their CVs. We classified the fields into 28 categories, using listings that appeared frequently on the CVs as the category names and grouping listings that appeared less frequently with the larger categories whenever possible. The average job candidate listed three of the twenty-eight fields on his or her CV. Twenty of these fields are listed in table 1. The five most frequently-listed fields are labor economics, macroeconomics, industrial organization, applied microeconomics, and applied econometrics, each of which was listed by between 21 and 23 percent of job candidates. In consideration of space, we have omitted fields listed by fewer than 5 percent of job candidates from the table.

The pre-market survey provides information about the private characteristics of job seekers, including their work-related preferences and expectations. For example, in all survey years we asked respondents to rank several types of jobs in order of their preference. ${ }^{\text {xiv }}$ Table 2 reports the percentage of job candidates who ranked jobs in each category as their mostpreferred outcome. A large majority (72 percent) of job candidates preferred assistant professorships at universities over jobs in all other categories. Relatively few (11 percent or less) preferred jobs in each of the other categories: research positions at non-profit, governmental, or quasi-governmental organizations; assistant professorships at four-year colleges; research positions at business or industry establishments; or postdoctoral fellowships.

The 2009-10 pre-market survey asked job candidates how "impressive" they expected their initial placement to be, relative to the placements of their peers in the same graduate department. In particular, the survey asked job candidates to place themselves in the appropriate decile of the placement distribution under the following scenario:

\footnotetext{
xiii Most (66 percent) job candidates from unranked departments were from lower-ranked economics departments in the United States. A sizable minority (30 percent) were from departments outside the United States, and a small number (4 percent) were from departments in fields closely related to economics, such as business or public policy.

${ }^{\mathrm{xiv}}$ The job type preference variable was not identical from year to year. Specifically, in the 2007-08 pre-market survey, we asked about preferences over job setting (university, 4-year college, postdoctoral fellowship, non-academic research and non-academic nonresearch), while in later years we asked about job types more specifically (Assistant professor at four-year college, Assistant professor at university, postdoctoral fellow, non-academic researcher (e.g., researcher at a think tank, government research unit, central bank, or international financial organization), private sector researcher). However, the descriptions were relatively similar, and a chi-square test of distribution in most-preferred job types between cohorts does not reject the null hypothesis that the distributions are identical (pvalue 0.45$)$.
} 
Imagine that, next year, the faculty in your department compile a list of the job placements of their graduates over the last five years. They put the placements they consider to be most impressive at the top of the list. Thinking about the kind of job you expect to obtain, where do you think you would fall in this list?

On average, job candidates are very optimistic about their prospects prior to the job market. As in Lake Wobegon, more than 80 percent of the job candidates who answered this question expected to place in the top half of the distribution for their graduate department (table 3). There is no apparent relationship between rank of respondent $\mathrm{PhD}$ program and expected placement ranking. ${ }^{\mathrm{XV}}$

Despite unrealistically optimistic expected "impressiveness" rankings overall, pre-market expected placement rankings are strongly related to post-market rankings of respondents' accepted jobs. A univariate regression of post-market placement ranking on expected placement ranking yields a coefficient on expected placement ranking of 0.48 (s.e.0.07). ${ }^{\mathrm{xvi}}$ The R-squared statistic for this regression is 0.23 . So, although job candidates generally think they will place unrealistically well relative to others in their departments, their premarket expectations of relative placement rank do have some predictive power about their post-market relative placement rank.

\section{Applications, interviews, and fly-outs}

In this section, we examine ways in which the economics job market for new PhDs operates to match job seekers with employers through a series of screens. Results from the Job Seekers surveys suggest that new economists apply to a large number of jobs, but that most of the applications they submit do not lead to offers from employers at later stages of the job market. Table 4 presents the mean number of applications job candidates submitted, the mean number of invitations they received for interviews and fly-outs, and the mean number of job offers they received. During the job-market seasons covered by this study, job candidates submitted 107 applications, completed 17 interviews and 6 fly-outs, and received 3 job offers on average. Our findings show a dramatic increase in applications compare to List (2000), who found the average job seeker in his convenience sample had scheduled just seven interviews prior to the AEA meetings in 1997. ${ }^{\text {xvii }}$ It is likely that the decreased cost of finding openings and submitting applications associated with of the growth of internet job listings and web-based applications have changed norms since the late 1990s.

The table also summarizes the yields of applications, interviews, and fly-outs, where these yields are defined as the proportion of job applications that lead to interview invitations, the proportion of interview invitations that lead to fly-out invitations, or the proportion of fly-out invitations that lead to job offers, respectively.

By the time the average job candidate traveled to first-round interviews, just 19 percent of the jobs to which he or she had applied remained in play. Just 8 percent of the jobs to which

\footnotetext{
${ }^{\mathrm{xv}}$ Pearson Chi-squared test statistic is 30.34 (36 d.f), $\mathrm{p}=0.734$. Correlation coefficient is -0.0074 . Coefficient from OLS regression of expected rank on rank of $\mathrm{PhD}$ institution is 0.009 (s.e. 0.09).

${ }^{\mathrm{XV1}}$ Regression conducted using two-wave weights. $\mathrm{N}=247$.

xvii It is possible that the job seekers who had time to participate in a survey during the AEA meetings had less busy interview schedules than other job seekers.
} 
the average job candidate applied resulted in a fly-out, and just 4 percent resulted in a job offer. While most of the applications new economists submit do not lead to offers from employers at later stages of the job market, the subset of applications that lead to an interview are reasonably likely to lead to a fly-out (37 percent chance) and, eventually, a job offer (20 percent chance). By the time the average job candidate reached the fly-out stage of the job market, his or her choice set contained a small number of promising options, 57 percent of which resulted in a job offer.

At each stage of the job market, some job candidates enjoy better success than others. Table 5 presents results from regressions of the percentage yields at the application, interview, and fly-out stages on a variety of job seeker characteristics. Research fields are also included in these regressions; in the interest of space, these estimates are located in appendix table 1. The estimates in table 5 suggest that characteristics associated with lower success rates at the earlier stages of the job market need not be associated with lower success rates in the final stage of the job market. In particular, the fly-outs of job candidates from lower-ranked departments and job candidates with more teaching experience are no less likely than the fly-outs of job candidates from top-ten departments and job candidates with less teaching experience to result in a job offer. ${ }^{\mathrm{x} v i i i}$

Column 1 displays results from a regression of the percentage yield of interviews per application on a variety of demographic and background variables from the CV data. At this stage, coming from a $\mathrm{PhD}$ program in economics is associated with a 7 percentage point lower yield of interviews per application, compared to $\mathrm{PhD}$ programs in economics-related fields other than economics. Less prestigious $\mathrm{PhD}$-granting departments are also associated with 2 to 7 percentage point lower yields relative to the most prestigious departments, though only the ranks of 21 to 30 and 41 to 50 are statistically-significantly different from those ranked 1 to 10. Number of publications also predicts higher yields at this stage: having three or more journal publications on one's $\mathrm{CV}$ is associated with a 7 percentage point higher yield of applications to interviews. Gender, undergraduate location, coming from a $\mathrm{PhD}$ program in the US, and teaching experience all have relatively small and imprecisely measured relationships to this yield.

Column 2 examines predictors of fly-outs per interview. Here, a $\mathrm{PhD}$ program in economics is still associated with a much lower yield at this stage, but the effect is not statisticallysignificant. As in the predictors of application-to-interview yield, less prestigious $\mathrm{PhD}$ programs are associated with lower interview-to-fly-out yield. Effect sizes range from 1.4 percentage points for programs ranked 11 to 20 to 9.8 percentage points for programs ranked 31 to 40 , but only the coefficients on programs ranked 21 to 30 and 31 to 40 are statistically significant at the 5 percent level or better. Gender, undergraduate location, $\mathrm{PhD}$ program location, journal publications, and teaching experience all have small and imprecisely estimated coefficients.

xviii: Excluding non-US PhD programs, significance patterns and signs from Table 5 are all the same, with one exception: courses as Primary Instructor became statistically significant at the $5 \%$ level in column 3 . The coefficient is 1.83 (s.e. 0.91 ). 
Column 3 examines the predictors of job offers per fly-out. At this stage, job candidates who earned their undergraduate degrees in Asia and those from less-prestigious institutions make up some, but not all, of their disadvantage from earlier stages of the market. ${ }^{\text {xix }}$ Gender, $\mathrm{PhD}$ program location, journal publications, and teaching experience all have relatively small and imprecisely-estimated coefficients.

Following table 5 from left to right, we notice that the R-squared statistics of the regressions decrease monotonically. That is, as the job market progresses from applications to interviews to fly-outs to job offers, the observable characteristics in these regressions explain less and less of the variation between job candidates, while factors that are unobservable or unmeasurable based on CV content, begin to matter more. These latter factors may become more observable to hiring committees and job candidates at the later stages of the market, as each position or candidate is examined in more detail. They may include fit of research interests or training with a particular job, interview skills, personality, or quality assessments of the reference letters, job-market papers, and presentations of job candidates.

Job candidates may wonder whether larger application, interview, or fly-out sets tend to yield more job offers. Data from the Job Seekers project suggest that they do, but that the marginal return to an additional application, interview, or fly-out decreases with the size of the existing set. Table 6 presents results from regressions of the number of job offers on quadratics in the number of applications, interviews, and fly-outs. The regressions include all background characteristics of job candidates from table 1 as control variables. In each column of table 6 , the estimated coefficient on the quadratic term is negative and statistically significant, consistent with decreasing marginal returns in job offers to prospective jobs at earlier stages of the market.

In column 1, number of applications is the explanatory variable of interest. At the mean number of applications in this sample (109), the marginal effect of an application on the number of job offers is 0.007 (s.e. 0.002). By contrast, around the $50^{\text {th }}$ application, an additional application yields an additional 0.010 job offers (s.e. 0.002 ), and around the $150^{\text {th }}$ application yields an additional 0.004 job offers (s.e. 0.001 ). The marginal effects of additional interviews (column 2) and fly-outs (column 3) follow similar patterns. However, at each successive stage of the job market, an additional option in one's choice set yields a greater chance of an additional job offer.

While the results in table 6 show a positive association between the number of job offers and the number of applications, interviews, and fly-outs in the cross section of new economists, they do not imply that individual job candidates can obtain more job offers by submitting more applications. The number of applications a job candidate submits may reflect

\footnotetext{
xix Despite higher yields from fly-outs to job offers, the average number of job offers to job candidates with Asian undergraduate degrees (2.5 job offers, s.e. 0.2) remains below that of those with degrees from other countries (3.2 job offers, s.e. 0.1). Given that job candidates from Asian undergraduate institutions apply to more jobs on average (110.6 applications, s.e. 5.3) than those from other locations (106.7 applications, s.e. 2.4), these job candidates have lower success rates than others between the application and fly-out stage.

Despite higher yields from fly-outs to job offers, the average number of job offers to job candidates from PhD programs ranked 21-50 (2.5 job offers, s.e. 0.1) remains below that of those from the top 20 programs (3.9 job offers, s.e. 0.2). Given that job candidates from lower-ranking programs apply to more jobs on average (120 applications, s.e.4.5) than those from higher-ranking programs (97.6 applications, s.e.3.6), these job candidates have lower success rates than others between the application and fly-out stage.
} 
idiosyncratic strategies for success on the job market, but is almost certainly responsive to demand-side factors as well. Job candidates who submit a large number of applications, and who receive a correspondingly large number of interviews, fly-outs, and job offers, may be job candidates whose skills are in demand by many employers. ${ }^{\mathrm{xx}}$

\section{Job outcomes}

The job market for new PhDs in economics and related fields remained quite strong between 2007 and 2010, despite the downturn. At the end of the market each year, almost all job candidates reported that they had accepted a position. Approximately 92 percent of job candidates accepted a job (s.e. 1 percent), while 1.9 percent rejected all offers (s.e. 0.4 percent). Just 6 percent had received no job offers at all (s.e. 0.9 percent). These results are broadly consistent with other available estimates. For example, Deck et al.(2011) recorded an 89 percent success rate among new PhDs seeking jobs in 2011 whose PhD-granting departments completed surveys, and Siegfried and Stock projected a 2 percent unemployment rate for the population of graduates (Siegfried and Stock 2004). This is unsurprising, as the National Science Foundation's Survey of Doctorate Recipients reported only 200 out of 27,600 total economics PhD respondents unemployed in 2013, indicating a very low unemployment rate of economics PhDs as a population (National Science Foundation 2014).

Table 7 presents statistics about the jobs candidates accepted. The placements of the majority of job candidates who accepted jobs mirrored the preferences they expressed at the beginning of the job-market season. In the end, most job candidates accepted a job of their preferred type. Panel A of table 7 displays the proportion of job placements by type, reported by job candidates at the post-market survey. By far the most common outcomes were assistant professorships at universities, ${ }^{\mathrm{xxi}}$ with 62 percent of placements falling into this category. In contrast, less than 20 percent of placements fell into each of the remaining categories: assistant professorships at four-year colleges, ${ }^{\text {xxii }}$ research positions at non-profit, governmental, or quasi-governmental organizations, research positions in business or industry establishments, ${ }^{\text {xxiii }}$ and postdoctoral fellowships. ${ }^{\text {xxiv }}$ These outcomes align surprisingly closely with the preferred job types shown in table 2 . The main departures were in jobs at universities and non-profit, governmental, or quasi-governmental organizations. Candidates were less likely to end up with positions at universities than would be expected if

\footnotetext{
$\mathrm{xx}_{\mathrm{For}}$ example, if the job postings in a given year disproportionately seek health economists, health economists are likely to respond by applying to a large number of jobs. Then, because demand for their skills is high, the applications of health economists are likely to be successful.

xxi We have included visiting assistant professor and lecturer positions at universities in this category. The "tenure track" statistics in Panel C provide some insight into this.

xxii We have included visiting assistant professor and lecturer positions at colleges in this category. The "tenure track" statistics in Panel C provide some insight into the fraction who are on the tenure track. Stock and Siegfried (2001) found that 6 percent of new $\mathrm{PhDs}$ about whom they received information about the 1996-97 market were employed in full-time permanent US positions at Carnegie B.A./B.S. institutions. This is close to our estimate of 8 percent. It should be noted that they only include "full-time permanent" positions, which excludes adjunct, lecturer, and visiting positions, whereas we include these positions here if the candidate so classified him/herself.

xxiii: Includes positions with consulting firms.

${ }^{\mathrm{xxiv}}$ Restricting to the candidates from US PhD institutions only, the only notable difference is that in table 7 a slightly lower percentage of job candidates prefer postdocs (3\% versus 5\% in the full sample), while $9 \%$ prefer colleges and $63 \%$ prefer universities. One possible explanation for this is that, for foreigners who want to get into the US job market, a postdoctoral fellowship is one way to make connections and improve English skills.
} 
all candidates received their most-preferred type (62 percent accepted a university job, while 72 percent ranked this job type as most preferred). They were more likely to end up with positions at non-profit, governmental, or quasi-governmental organizations than would be expected if all candidates received their most-preferred type (19 percent accepted such a job, while only 11 percent ranked this job type as most preferred).

A direct test of how well preferences reported in the pre-market survey align with outcomes reported in the post-market survey is to examine alignment at the level of the individual job candidate. Panel B of table 7 shows that almost two-thirds of job candidates placed into their first-choice job types (64 percent), while 20 percent placed into their second-choice job types and 9 percent placed into their third-choice job types. Just 7 percent of job candidates placed into job types that they had ranked as their fourth- or fifth-most preferred out of the five job types.

Most jobs reported by job candidates were also on the tenure track (panel C), though those with positions at four-year colleges were a bit less fortunate in this regard than those with university positions ( 78 percent versus 86 percent on the tenure track).

While placing into one's preferred pre-market job type is one indicator of success in the job market, it is also possible that preferences might change throughout the process, or that idiosyncratic characteristics may make preferences for particular jobs different from general preferences. To provide a subjective measure of success on the job market that is robust to these concerns, the post-market survey asks respondents to rate their satisfaction with their accepted job on a six-point scale, from "extremely dissatisfied" (1) to "extremely satisfied" (6). Table 8 shows that candidates are on average "very satisfied" with the outcomes of their job search. The mean ratings are very similar across categories asking about satisfaction with the job, "overall," in terms of intellectual fit, social fit, compensation, and work load. Examining the overall satisfaction ratings in terms of the proportion of candidates giving each rating, more than two-thirds of job candidates who accepted jobs were "very" or "extremely" satisfied with their placements in the end (69.1 percent). Another quarter were "somewhat" satisfied (24.4 percent). Very few (just 7 percent) of job candidates who accepted jobs reported being "extremely," "very," or even "somewhat" dissatisfied with the outcome.

Another important outcome measure is compensation. While compensation is not an extremely important factor in most junior $\mathrm{PhD}$ economists' job choices, ${ }^{\mathrm{xxv}}$ jobs do tend to be well-paid. Table 9 displays mean salary in 2010 dollars for all cohorts together, both overall and by job type. The average base salary among all accepted jobs is just under $\$ 93,000$. At $\$ 88,600$, the median base salary is quite close to the mean and almost exactly at the midpoint of the interquartile range ( $\$ 68,900$ to $\$ 109,000$ ), indicating a distribution that is relatively symmetric. The mean and median are extremely similar to inflation-adjusted figures from the 2001 job market presented by Siegfried and Stock (2004), in which the mean salary works out to about $\$ 92,600$ in 2010 dollars, and the median to $\$ 89,500$. xxvi

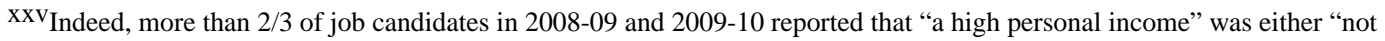
important," "a little important," or "moderately important." Only a quarter rated high income as being "very important," and 7 percent rated it "extremely important." 
Salaries vary dramatically by job type; this might suggest compensating differentials related to lifestyle or prestige, or simply indicate different norms across types of institutions and positions. Positions in business and industry tend to be the highest paid, at $\$ 110,100$ on average, while postdoctoral fellowships, the lowest-paid category, average just $\$ 57,500$. The average salary for a four-year college position is $\$ 72,400$, while the average new assistant professor's salary at a university is $\$ 96,500$ per year. The estimates for university jobs are quite similar to inflation-adjusted reports presented in Deck, et al. (2011). There are broad interquartile ranges for all job types, indicating that salaries vary dramatically from job to job even within job categories. ${ }^{\text {xxvii }}$

\section{Predictors of job characteristics}

While summary statistics provide a nice overview of job outcomes, outcomes vary across subgroups. Tables 10,11 and 12 provide some insight into predictors of job type, salary and job satisfaction.

To examine the predictors of job type, we conducted multinomial logistic regressions with job types as the outcome variables. Assistant professorships at universities, being the modal preferred and actual outcomes, are the base category against which the relative risk ratios (that is, the exponentiated coefficients, $\mathrm{e}^{\beta \mathrm{i}}$ ) for other outcomes are estimated.

Overall, table 10 highlights the importance of preferences in predicting job outcomes. With respect to job-type preferences, job candidates who do not prefer university jobs are more likely to end up with other types of jobs. Additionally, measures of teaching experience, which might be thought of as providing measures of revealed preference or aptitude for teaching versus research activities, are related to job outcomes in expected ways. Candidates who were primary instructors during graduate school revealed a strong preference to teach or aptitude for teaching, and, indeed were more likely to end up at teaching-oriented colleges over universities, and less likely to end up in business or industry establishments over university jobs, relative to candidates without primary instruction experience. Candidates whose graduate studies were funded by teaching assistantships, presumably an alternative to research assistantships, are less likely to end up in research-oriented academia. Below, we elaborate on the factors that are predictive of the likelihood of ending up in each job type, relative to a job at a university. ${ }^{\text {xxviii }}$

${ }^{x x v i}$ Calculated using the Bureau of Labor Statistics' CPI-U for June 2001 and June 2010 (CPI 2014).

xxvii: All quantiles are virtually identical when excluding those from non-US PhD institutions. Means are $\$ 1,500$ to $\$ 2,000$ higher when restricting to US PhDs. However, even the overall mean, which is $\$ 2,000$ different and has the largest sample size, is not statistically significantly larger than that of the main sample ( $\mathrm{p}$-value $=0.12$ ).

xxviii: Results do change when excluding non-US PhDs. In this discussion, I only discuss results that changed the take-aways from this table. In column 1, the estimate for "Preferred job type: NGQO" dropped to 4.68 (s.e 2.89, significant at the 1\% level). That is, for candidates who preferred a job at an NGQO, they were about 5 times more likely to end up at a college than a university. This is half the effect size as is presented in the table, but in the same direction. Additionally the relative risk ratio for unranked PhD programs increased to 3.48 (s.e. 2.14), becoming statistically significant at the 1 percent level. Column 2 was virtually identical. In column 3 , the estimate on "Preferred job type: NGQO" more than doubled, to 117, and the coefficient on "Preferred job: Postdoc" tripled (to 38.45, s.e. 62.9) and became significant at the 5 percent level. These findings lend more support to our finding that an openness to jobs outside traditional academia greatly increases the chances of ending up in a non-academic job. In column 4, the estimate on "Preferred job type: NGQO" changed to almost zero, and is statistically significant, indicating that US PhDs who prefer NGQO jobs virtually never end up in postdoctoral fellowships. The estimate on "Preferred job: Postdoc" also increased fivefold (to 105.9, s.e. 175.11), indicating that a US PhD who prefers a postdoc is many, many times more likely to end up in a postdoc over a university job. This is statistically significant at the 0.1 percent level. The estimates on lower-ranking PhD programs also increased. Additionally, three or more journal publications was associated with close to no chance of ending up at a postdoc over a university $(0.00$, s.e. 0.00$)$. 
Column 1 of table 10 displays the relative risk ratio estimates of assistant professorships at four-year colleges over assistant professorships at universities. For example, the estimate on the indicator variable for whether a job candidate's most preferred job type is assistant professor at a four-year college is statistically different from zero at the 1 percent level. It indicates that job candidates who prefer college jobs are 5 times more likely than otherwise comparable candidates to end up with a job at a college over a job at a university. The estimates show that candidates who prefer non-university jobs relative to university jobs, and candidates with more experience as a primary instructor, are more likely to end up with a job at a college over a job at a university. In contrast, those with an undergraduate education from outside of the United States and Asia are less likely to end up at a college over a job at a university. Gender, undergraduate education in Asia, $\mathrm{PhD}$ program in economics, institution rank, journal publications and number of courses as a teaching assistant are not statistically significant predictors of having college jobs over university jobs.

Estimates in Column 2 reflect the relative risk ratios of jobs at non-profits, governmental, and quasi-governmental organizations over university job outcomes. In this column, the relative risk ratio estimates show that a preference for jobs in non-profit, governmental, or quasi-governmental organizations and a preference for jobs at business or industry establishments are associated with a greater likelihood of the former job over a university. In contrast, a preference for a postdoctoral fellowship relative to other types of jobs is associated with a reduced chance of a job at a non-profit, governmental, or quasigovernmental organization over a university job.

Column 3 displays the relative risk ratios of research positions at business or industry establishments over assistant professorships at universities. Here, the estimates show that a preference to end up in any type of job other than a university job or postdoctoral fellowship is associated with a greater chance of ending up in job at a business or industry establishment over a university job. This might be reflective of the common perception that it is harder to move back into academia from business than from other types of jobs: job candidates who might ever want to work in academia may have a stronger preference to avoid this type of job.

In Column 4, preferring postdoctoral fellowships relative to other types of jobs increases the relative risk of a postdoctoral fellowship, relative to a university job.

Table 11 presents estimates from linear regressions of salary on our base set of covariates and additional predictors of salary, where salary is measured in thousands of 2010 dollars. The R-squared statistic from this regression (0.50) reveals surprisingly good predictive power.

It can be seen that gender is not a statistically significant predictor of salary, holding other variables constant. However, an undergraduate education outside the United States is associated with a significantly lower salary, compared to an undergraduate education in the United States. These differences are quite large: almost $\$ 15,000$ for those with undergraduate degrees from Asia, and \$5,800 for those from other countries. ${ }^{\text {xxix }}$ This finding may reflect two effects. First, job candidates from outside the United States may be 
more likely to accept jobs outside of the United States, where salaries are lower. Second, lower English fluency is likely correlated with having pursued undergraduate studies outside the United States, and may therefore be associated with poorer job outcomes.

Candidates whose job-market information was posted on the website of an economics department earn around $\$ 25,000$ less than other candidates. This is likely due to the fact that some of the other candidates are from business schools, where jobs in business schools or private industry (and the accompanying large paychecks) are common job outcomes.

Rank of PhD program is strongly associated with salary. Holding all else constant, job candidates from programs ranked in the top ten reported the highest salaries. Compared with job candidates from programs ranked in the top ten, job candidates from programs ranked 11-20 reported salaries that were almost $\$ 6,000$ lower, on average; job candidates from programs ranked in 21-30 reported salaries that were $\$ 11,000$ lower; and job candidates from programs ranked below 30 reported salaries that were between $\$ 18,000$ and $\$ 20,000$ lower.

Job type is, not surprisingly, related to salary even after holding other factors constant. Compared with assistant professorships at universities, postdoctoral fellowships are associated with salaries that are $\$ 25,000$ lower, on average, and college jobs are associated with salaries that are $\$ 9,000$ lower. In contrast, jobs at business or industry establishments are associated with salaries that are $\$ 15,000$ higher.

In addition to job type, the number of job offers a job candidate receives may influence salary for several reasons. First, receiving more job offers increases the chance of a particularly good job outcome. If a high salary is desirable, a larger choice set should be associated with increased salary. Second, the number of job offers a job candidate receives is likely a strong indicator of quality, so should be associated with better job outcomes, including higher salary. Third, job candidates with multiple job offers have more bargaining power with which to negotiate higher salary offers, and so more job offers may actually result in higher salary offers. The coefficients on the number of job offers indicate that the greater the number of job offers, the higher the salary. However, the negative coefficient on the number of job offers squared indicates that the marginal effect of job offers on salary is largest for the first few job offers. Overall, the average marginal effect of an additional job offer is $\$ 5,600$ (s.e. $\$ 600$ ). At the second job offer, the average marginal effect of an offer is $\$ 6,400$ (s.e. $\$ 800$ ), while at the fifth job offer the average marginal effect is $\$ 4,500$ (s.e. $\$ 500)$.

Because salary is not the only characteristic job candidates care about, we have also examined job candidates' satisfaction with their job outcomes. As shown in table 8 , candidates tend to be satisfied with their job outcomes. Table 12 presents estimates of average marginal effects from a probit regression using the base set of covariates plus the preference ranking of the accepted job and a quadratic in number of job offers. The

xxix The coefficient on "Undergraduate location: Other" decreased in magnitude, to -4.64 (s.e. 2.59) and lost its statistical significance when using only the US PhD sample. There are no other changes in significance level, and all statistically-significant coefficients are within 10 percent of the value shown in Table 11. 
dependent variable in this regression, "highly-satisfied," is an indicator variable that is equal to one if a job candidate reported being "extremely" or "very" satisfied with the accepted job. This variable is equal to zero if the candidate reported being less than "very" satisfied.

Overall, the descriptive analysis of satisfaction, together with this regression, shows that job candidates tend to be quite satisfied with their job outcomes. Just over two-thirds of candidates reported being highly satisfied ( 68 percent, s.e. 3 percent). Variation in satisfaction between subgroups of the job candidate population is mostly fairly small, and tends to run in the expected direction.

We expect the number of job offers to be positively related to satisfaction, since a larger number of offers may include better draws from the distribution of jobs. Indeed, the number of job offers is positively associated with satisfaction, with an additional job offer associated with about a 4 percentage point increase in the chance a job candidate is "very" satisfied. Another measure of a "good draw" of job options is the preference-ranking of the type of job the candidate eventually accepted. Here, the less-preferred the type of the job, the less likely the respondent was to be highly satisfied, though the estimates are mostly relatively imprecisely estimated.

Job candidates from undergraduate institutions in Asia are also 14 percentage points less likely to rate themselves as "very" satisfied than others. Additionally, candidates from lowerranked programs tend to report lower satisfaction with their job placements; candidates from $\mathrm{PhD}$ programs ranked between 21 and 30 are 16 percentage points less likely than those from the top ten programs to rate themselves as "very" satisfied. ${ }^{\mathrm{xxx}}$

\section{Conclusions}

This paper updates existing work about the new $\mathrm{PhD}$ job market in economics by presenting findings about the 2007-2010 job market years. Results from the Job Seekers Project confirm prior findings that, even in lean years, new $\mathrm{PhD}$ economists can expect to be successful on the job market that functions around the ASSA meetings each January.

This paper takes advantage of longitudinal features of the Job Seekers Project to examine how pre-market preferences and expectations align with outcomes. We show that the job candidates who most want a given type of job are more likely than others to secure that type of job, and nearly two thirds of job candidates secure jobs of their first-choice type of job. At the beginning of the job market, few job candidates report that they expect to do poorly; at the end, few report that they are dissatisfied with key aspects of their placement. Furthermore, job candidates' expectations at the beginning of the market are somewhat predictive of outcomes at the end.

The detailed data from a representative sample frame also allow us to draw conclusions about subgroups of the population. While some characteristics of job candidates, such as receipt of undergraduate training in Asia and receipt of doctoral training at lower-ranked

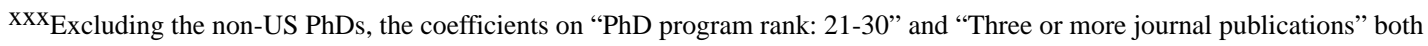
declined by less than 10 percent, and lost their marginal statistical significance. 
departments, are associated with smaller choice sets, lower salaries, and lower levels of satisfaction, job candidates in all groups generally achieve positive outcomes.

\section{Acknowledgments}

We gratefully acknowledge support from the Sloan Foundation's Scientific \& Engineering Workforce Program, the Eva L. Mueller New Directions in Economics and Demography Fund, and the A. Regula Herzog Young Investigators' Fund. We are thankful for feedback from Charlie Brown, David Lam and Miles Kimball about the Job Seekers Project and its surveys, and we thank Martha Bailey, Trivellore Raghunathan, Jeffrey Smith, and Matthew Shapiro for comments and feedback about this paper.

\section{Appendices}

\section{Appendix Table 1 \\ Excluded rows from Table 5: Predictors of percent yield by stage of the market}

\begin{tabular}{|c|c|c|c|}
\hline & Interviews per Application & Fly-outs per Interview & Job offers per Fly-out \\
\hline Applied econometrics & $0.795(1.350)$ & $-0.225(2.128)$ & $3.296(2.788)$ \\
\hline Applied microeconomics & $-1.735(1.000)$ & $3.338(2.068)$ & $0.602(2.589)$ \\
\hline Behavioral economics & $2.233(3.659)$ & $5.725(3.760)$ & $-2.104(4.761)$ \\
\hline Computational economics & $-0.117(2.192)$ & $7.207(4.230)$ & $2.172(5.644)$ \\
\hline Development economics & $-1.153(1.353)$ & $-1.936(2.097)$ & $4.11(2.860)$ \\
\hline Econometrics & $0.113(1.487)$ & $-1.75(2.027)$ & $1.161(3.195)$ \\
\hline Economic history & $-4.215^{*}(2.137)$ & $-0.877(4.888)$ & $-5.583(6.177)$ \\
\hline Economic theory & $-1.892(2.378)$ & $-1.001(5.194)$ & $11.700 *(5.742)$ \\
\hline Economics of education & $-0.86(2.525)$ & $0.359(3.688)$ & $10.940 *(4.580)$ \\
\hline Environmental economics & $3.516(2.166)$ & $0.968(3.605)$ & $-0.964(4.381)$ \\
\hline Experimental economics & $-4.016(2.412)$ & $2.307(3.457)$ & $5.153(4.852)$ \\
\hline Financial economics & $1.749(1.472)$ & $-2.492(2.559)$ & $-5.629(3.375)$ \\
\hline Game theory & $1.061(1.945)$ & $-1.51(3.076)$ & $1.848(4.739)$ \\
\hline Health economics & $-0.401(1.419)$ & $3.774(2.718)$ & $4.858(3.670)$ \\
\hline Industrial organization & $-1.516(1.215)$ & $-2.133(2.131)$ & $2.321(2.736)$ \\
\hline Int'l economics & $-0.559(1.608)$ & $-2.754(2.567)$ & $-1.75(4.052)$ \\
\hline International finance & $-2.951(2.109)$ & $-1.669(2.919)$ & $-0.838(4.040)$ \\
\hline International macro & $2.184(4.609)$ & $6.562(5.637)$ & $-9.158(6.036)$ \\
\hline International trade & $-1.422(1.812)$ & $0.417(3.057)$ & $-4.988(3.466)$ \\
\hline Labor economics & $-1.854(1.154)$ & $-1.134(1.924)$ & $-1.701(2.668)$ \\
\hline Law and economics & $-6.729^{* * *}(2.035)$ & $-10.554^{* * * *}(2.908)$ & $1.909(6.305)$ \\
\hline Macroeconomics & $0.834(1.496)$ & $-5.790^{* *}(2.241)$ & $5.86(3.265)$ \\
\hline Microeconomic theory & $-3.981^{* *}(1.489)$ & $-2.961(2.623)$ & $0.887(4.048)$ \\
\hline Microeconomics & $2.756(2.714)$ & $4.83(3.542)$ & $-2.177(5.352)$ \\
\hline Monetary economics & $0.063(1.969)$ & $-6.015(3.100)$ & $-12.903^{* *}(4.619)$ \\
\hline Political economy & $1.843(1.695)$ & $3.736(3.079)$ & $4.238(3.716)$ \\
\hline Public economics & $-0.674(1.133)$ & $-2.73(2.149)$ & $-0.348(2.743)$ \\
\hline Urban economics & $-2.914(1.843)$ & $-1.802(3.258)$ & $4.975(6.738)$ \\
\hline
\end{tabular}

JEcon Educ. Author manuscript; available in PMC 2016 September 09. 
Notes: Results from OLS regressions. Dependent variables are percent (0 to 100) of: applications resulting in an interview invitation (column 1), interviews resulting in a fly-out invitation (column 2), and fly-outs resulting in a job offer (column 3). Results are weighted using post-market weights.

* $\mathrm{p}<.05$;

*** $\mathrm{p}<.01$

**** $\mathrm{p}<001$

Appendix Table 2

Excluded rows from Table 6: Marginal return in job offers from an additional application, interview or flyout

\begin{tabular}{|c|c|c|c|}
\hline Explanatory Variable & Applications & Interviews & Fly-outs \\
\hline Female & $0.17024(0.16950)$ & $0.07038(0.14614)$ & $-0.12113(0.10426)$ \\
\hline Undergrad: Asia & $-0.45794 *(0.20000)$ & $-0.06546(0.16686)$ & $0.23113(0.12521)$ \\
\hline Undergrad: Other & $-0.19189(0.19344)$ & $0.09846(0.15855)$ & $0.04392(0.12400)$ \\
\hline $\mathrm{PhD}$ in US & $-0.17203(0.32325)$ & $-0.03941(0.24738)$ & $-0.07499(0.17794)$ \\
\hline $\mathrm{PhD}$ in economics & $-0.03045(0.31881)$ & $0.0058(0.22194)$ & $0.20486(0.20068)$ \\
\hline Rank: 11 to 20 & $-0.59889^{*}(0.26685)$ & $-0.42773(0.23329)$ & $-0.18964(0.17127)$ \\
\hline Rank: 21 to 30 & $-1.32259^{* * * *}(0.26433)$ & $-0.99804^{* * * *}(0.22231)$ & $-0.2864(0.18294)$ \\
\hline Rank: 31 to 40 & $-1.24653^{* * *}(0.28714)$ & $-0.56149^{*}(0.24945)$ & $0.08831(0.17440)$ \\
\hline Rank: 41 to 50 & $-1.40560^{* * *}(0.28920)$ & $-0.53774 *(0.25151)$ & $0.02807(0.18349)$ \\
\hline Rank: Unranked & $-1.61116^{* * *}(0.23903)$ & $-0.76829^{* * *}(0.19670)$ & $-0.22263(0.15781)$ \\
\hline 1 Journal Pub & $0.17668(0.19666)$ & $0.04553(0.16313)$ & $0.05368(0.12423)$ \\
\hline 2 Journal Pubs & $0.14227(0.28985)$ & $-0.05558(0.26026)$ & $0.01822(0.21809)$ \\
\hline 3+ Journal Pubs & $0.45752(0.35198)$ & $0.36069(0.29774)$ & $0.13984(0.20416)$ \\
\hline TA Courses, topcoded at 10 & $-0.04098(0.03219)$ & $-0.02698(0.02555)$ & $0.00504(0.02122)$ \\
\hline PI Courses, topcoded at 5 & $-0.09149(0.04768)$ & $-0.05301(0.04134)$ & $-0.00604(0.02988)$ \\
\hline Constant & $3.18530^{* * * *}(0.50800)$ & $0.98541 *(0.39581)$ & $0.05088(0.33393)$ \\
\hline Applied econometrics & $0.36533(0.20501)$ & $0.07625(0.17187)$ & $0.06341(0.12708)$ \\
\hline Applied microeconomics & $0.28626(0.18710)$ & $0.22426(0.16340)$ & $0.17267(0.12491)$ \\
\hline Behavioral economics & $-0.17869(0.35159)$ & $-0.14647(0.25867)$ & $-0.31877(0.20960)$ \\
\hline Computational economics & $0.74345(0.50592)$ & $0.67565(0.39260)$ & $0.17699(0.34062)$ \\
\hline Development economics & $-0.09398(0.18805)$ & $-0.01923(0.16267)$ & $0.11453(0.11960)$ \\
\hline Econometrics & $0.05724(0.20878)$ & $-0.11015(0.17217)$ & $-0.10205(0.12388)$ \\
\hline Economic history & $-0.68423(0.35808)$ & $-0.43641(0.25800)$ & $-0.34338(0.20604)$ \\
\hline Economic theory & $0.82687(0.72992)$ & $0.76492(0.64773)$ & $0.89241 *(0.40583)$ \\
\hline Economics of education & $0.173(0.36404)$ & $0.3231(0.31397)$ & $0.44548(0.23739)$ \\
\hline Environmental economics & $-0.05562(0.27127)$ & $-0.12152(0.22128)$ & $-0.06857(0.17939)$ \\
\hline Experimental economics & $0.0853(0.31842)$ & $0.2986(0.26861)$ & $0.25454(0.20200)$ \\
\hline Financial economics & $0.15054(0.22723)$ & $-0.24027(0.20105)$ & $-0.0975(0.14590)$ \\
\hline Game theory & $-0.27103(0.26977)$ & $-0.28781(0.23421)$ & $-0.1272(0.18961)$ \\
\hline Health economics & $0.98259^{* *}(0.31594)$ & $0.68524^{*}(0.27782)$ & $0.34297(0.20927)$ \\
\hline Industrial organization & $-0.03789(0.19400)$ & $0.03425(0.16199)$ & $0.10547(0.11287)$ \\
\hline International economics & $0.20704(0.27989)$ & $0.03856(0.24306)$ & $0.12472(0.16847)$ \\
\hline International finance & $0.28492(0.35467)$ & $0.21374(0.29347)$ & $0.31477(0.21818)$ \\
\hline
\end{tabular}

$J$ Econ Educ. Author manuscript; available in PMC 2016 September 09. 


\begin{tabular}{lccc}
\hline Explanatory Variable & Applications & Interviews & Fly-outs \\
\hline International macro & $-0.0855(0.48078)$ & $-0.21509(0.42560)$ & $-0.52293(0.38595)$ \\
International trade & $0.11083(0.27806)$ & $-0.07922(0.23526)$ & $-0.26407(0.18169)$ \\
Labor economics & $0.15576(0.19297)$ & $0.10402(0.16515)$ & $0.10398(0.11778)$ \\
Law and economics & $-0.98365^{* *}(0.33895)$ & $-0.68584^{* *}(0.25515)$ & $-0.25382(0.17566)$ \\
Macroeconomics & $-0.03658(0.23604)$ & $-0.30297(0.19909)$ & $-0.04692(0.13476)$ \\
Microeconomic theory & $0.03652(0.26271)$ & $0.12933(0.22989)$ & $0.21005(0.16860)$ \\
Microeconomics & $0.05381(0.35120)$ & $0.17708(0.30641)$ & $-0.06294(0.20970)$ \\
Monetary economics & $-0.27844(0.35037)$ & $-0.43018(0.28207)$ & $-0.27435(0.21307)$ \\
Political economy & $0.40987(0.24527)$ & $0.31556(0.19266)$ & $0.13345(0.14391)$ \\
Public economics & $-0.00292(0.19317)$ & $-0.26622(0.17416)$ & $-0.06244(0.12650)$ \\
Urban economics & $0.14792(0.43734)$ & $0.14535(0.38370)$ & $0.06308(0.34280)$
\end{tabular}

Notes: Results from OLS regressions. Dependent variable in all columns is number of job offers. In column 1, the explanatory variable of interest ("X variable") is number of applications, in column 2 it is number of fly-outs, and in column 3 it is number of fly-outs. Squared terms are included for explanatory variables of interest in each regression. Estimates are weighted using post-market survey weights.

* $<<.05$;

***

$\mathrm{p}<.01 ;$

$\mathrm{p}<.001$

Appendix Table 3

Excluded rows from Table 10: Multinomial logistic regression: Predictors of accepted job type

\begin{tabular}{|c|c|c|c|c|}
\hline & College & NGQO & Business & Postdoc \\
\hline Applied econometrics & $0.56(0.26)$ & $0.53(0.20)$ & $0.58(0.40)$ & $0.94(0.60)$ \\
\hline Applied microeconomics & $1.09(0.55)$ & $1.04(0.38)$ & $1.24(0.71)$ & $0.51(0.35)$ \\
\hline Behavioral economics & $1.25(1.42)$ & $0.19(0.19)$ & $0.19(0.34)$ & $0.14(0.19)$ \\
\hline Computational economics & $2.25(3.80)$ & $0.12(0.15)$ & $33.32^{* * *}(31.46)$ & $0.00^{* * *}(0.00)$ \\
\hline Development economics & $1.2(0.57)$ & $0.72(0.31)$ & $0.47(0.34)$ & $1.09(0.74)$ \\
\hline Econometrics & $3.87^{*}(2.02)$ & $1.07(0.44)$ & $0.62(0.53)$ & $1.11(0.75)$ \\
\hline Economic history & $3.09(2.67)$ & $0.84(0.64)$ & $2.42(2.99)$ & $0.00^{* * *}(0.00)$ \\
\hline Economic theory & $0.00^{* * *}(0.00)$ & $0.00^{* * *}(0.00)$ & $0.00^{* * *}(0.00)$ & $4.4(6.36)$ \\
\hline Economics of education & $0.45(0.36)$ & $1.69(0.86)$ & $0.45(0.49)$ & $6.63(9.60)$ \\
\hline Environmental economics & $2.45(1.55)$ & $0.82(0.40)$ & $0.33(0.33)$ & $7.34^{*}(6.40)$ \\
\hline Experimental economics & $1.14(0.94)$ & $0.26(0.21)$ & $0.93(1.12)$ & $2.66(2.59)$ \\
\hline Financial economics & $0.26(0.24)$ & $1.45(0.71)$ & $3.99(3.07)$ & $1.41(1.19)$ \\
\hline Game theory & $0.00^{* * *}(0.00)$ & $1.21(0.73)$ & $1.93(2.02)$ & $0.17(0.17)$ \\
\hline Health economics & $1.03(0.67)$ & $0.81(0.34)$ & $1.08(0.78)$ & $2.58(2.73)$ \\
\hline Industrial organization & $0.25^{*}(0.15)$ & $0.7(0.27)$ & $1.1(0.74)$ & $2.54(1.63)$ \\
\hline International economics & $0.58(0.44)$ & $0.29(0.19)$ & $0.00^{* * *}(0.00)$ & $1.72(1.45)$ \\
\hline International finance & $2.69(2.24)$ & $3.58(2.55)$ & $5.13(4.32)$ & $2.36(2.32)$ \\
\hline International macro & $0.91(1.00)$ & $1.17(0.64)$ & $0.00^{* * *}(0.00)$ & $0.76(0.79)$ \\
\hline International trade & $1.35(1.00)$ & $0.06^{* * *}(0.06)$ & $0.4(0.46)$ & $2.52(2.98)$ \\
\hline Labor economics & $1.5(0.75)$ & $0.86(0.30)$ & $1.65(0.96)$ & $0.53(0.44)$ \\
\hline
\end{tabular}

J Econ Educ. Author manuscript; available in PMC 2016 September 09. 


\begin{tabular}{lcccc}
\hline & College & NGQO & Business & Postdoc \\
\hline Law and economics & $0.87(0.82)$ & $0.39(0.27)$ & $1.85(1.74)$ & $0.00^{* * *}(0.00)$ \\
Macroeconomics & $1.18(0.75)$ & $1.58(0.79)$ & $0.9(0.67)$ & $2.92(2.57)$ \\
Microeconomic theory & $1.03(0.89)$ & $1.31(0.69)$ & $0.34(0.73)$ & $0.87(0.80)$ \\
Microeconomics & $1.83(1.56)$ & $0.8(0.56)$ & $0.00^{* * * *}(0.00)$ & $2.13(2.62)$ \\
Monetary economics & $1.1(0.68)$ & $1.21(0.55)$ & $0.25(0.23)$ & $0.39(0.51)$ \\
Political economy & $0.83(0.38)$ & $1.46(0.50)$ & $1.08(0.77)$ & $0.65(0.54)$ \\
Public economics & $0.00^{* * *}(0.00)$ & $0.22(0.28)$ & $0.92(0.83)$ & $15.93^{* *}(13.92)$ \\
Urban economics & $0.67(0.34)$ & $1.17(0.48)$ & $0.13^{* * *}(0.09)$ & $2.4(1.49)$ \\
Constant & $0.00^{* * *}(0.01)$ & $0.2(0.20)$ & $0.00^{* *}(0.01)$ & $0.1(0.14)$
\end{tabular}

Notes: Regression uses 661 observations. Base outcome category is "Assistant professor at university." Relative risk ratios are reported. Excluded categories are: "Undergraduate location: US," PhD program rank "1 to 10," and "0" journal publications. Regression also includes a constant and indicator variables for 28 research fields as additional controls; these are omitted in the interest of space. Estimates are weighted using survey weights to correct for non-response to one or both surveys. "NGQO" refers to a non-profit, governmental, or quasi-governmental organization.

p $<.05$;

*** $\mathrm{p}<.01$;

$* * *$

$\mathrm{p}<.001$

Appendix Table 4

Excluded rows from Table 11: Predictors of salary

\begin{tabular}{lc}
\hline & Salary \\
\hline Applied econometrics & $-3.2(2.45)$ \\
Applied microeconomics & $-0.67(2.39)$ \\
Behavioral economics & $7.5(5.25)$ \\
Computational economics & $4.73(7.99)$ \\
Development economics & $-4.51(2.53)$ \\
Econometrics & $-3.49(2.70)$ \\
Economic history & $-0.66(5.54)$ \\
Economic theory & $-8.6(6.64)$ \\
Economics of education & $-7.40 *(3.51)$ \\
Environmental economics & $-6.36^{*}(2.95)$ \\
Experimental economics & $-5.39(4.32)$ \\
Financial economics & $19.40 * *(3.76)$ \\
Game theory & $1.65(4.72)$ \\
Health economics & $-6.39(3.30)$ \\
Industrial organization & $0.64(2.35)$ \\
International economics & $1.87(3.42)$ \\
International finance & $3.61(4.55)$ \\
International macroeconomics & $-10.4(5.80)$ \\
International trade & $-0.21(3.31)$ \\
Labor economics & $-2.4(2.40)$ \\
Law and economics & $9.26(5.69)$ \\
Macroeconomics & $-0.36(3.01)$ \\
&
\end{tabular}

JEcon Educ. Author manuscript; available in PMC 2016 September 09. 


\begin{tabular}{lc}
\hline & Salary \\
\hline Microeconomic theory & $-2.69(3.69)$ \\
Microeconomics & $-5.03(3.65)$ \\
Monetary economics & $-8.44^{*}(4.18)$ \\
Political economy & $-5.51(3.70)$ \\
Public economics & $1.43(2.64)$ \\
Urban economics & $-3.14(4.88)$
\end{tabular}

Notes: Results from OLS regression. Dependent variable is salary in thousands of 2010 dollars. Estimates are weighted using survey weights to correct for non-response.

p $<.05$;

$\mathrm{p}<.01$

**** $\mathrm{p}<.001$

Appendix Table 5

Excluded rows from Table 12: Predictors of high satisfaction with job outcome

\begin{tabular}{lc}
\hline & Highly Satisfied (0/1) \\
\hline Applied econometrics & $-0.03(0.06)$ \\
Applied microeconomics & $0.1(0.06)$ \\
Behavioral economics & $-0.11(0.13)$ \\
Computational economics & $-0.04(0.12)$ \\
Development economics & $0.01(0.06)$ \\
Econometrics & $-0.09(0.07)$ \\
Economic history & $-0.14(0.10)$ \\
Economic theory & $-0.18(0.15)$ \\
Economics of education & $0.18(0.12)$ \\
Environmental economics & $-0.16(0.09)$ \\
Experimental economics & $0.15(0.13)$ \\
Financial economics & $-0.07(0.07)$ \\
Game theory & $0.16(0.10)$ \\
Health economics & $0.14(0.08)$ \\
Industrial organization & $-0.04(0.06)$ \\
International economics & $0.08(0.09)$ \\
International finance & $-0.12(0.11)$ \\
International macroeconomics & $0.25(0.18)$ \\
International trade & $0.11(0.09)$ \\
Labor economics & $-0.06(0.06)$ \\
Law and economics & $0.19(0.14)$ \\
Macroeconomics & $-0.04(0.07)$ \\
Microeconomic theory & $-0.03(0.09)$ \\
Microeconomics & $-0.14(0.11)$ \\
Monetary economics & $0.22(0.12)$ \\
Political economy & $0.01(0.09)$ \\
&
\end{tabular}

$J$ Econ Educ. Author manuscript; available in PMC 2016 September 09. 


\begin{tabular}{lc}
\hline & Highly Satisfied (0/1) \\
\hline Public economics & $0.02(0.06)$ \\
Urban economics & $0.16(0.12)$
\end{tabular}

Notes: Results from probit regression, average marginal effects reported. Dependent variable is equal one if job candidate reported being "extremely" or "very" satisfied with the accepted job. Estimates are weighted using survey weights to correct for non-response.

p $<.05$;

*** $\mathrm{p}<.01$ **** $\mathrm{p}<.001$

\section{References}

Barbezat DA. The Market for New Ph.D. Economists. Journal of Economic Education. 1992; 23(3): 262-276.

Carson R, Navarro P. A Seller's (\& Buyer's) Guide to the Job Market for Beginning Academic Economists. The Journal of Economic Perspectives. 1988; 2(2):137-148.

Cawley, J. A Guide and Advice for Economists on the U.S Junior Academic Job Market. 2014. https:// www.aeaweb.org/joe/pdfs/Job\%20Market\%20Guide\%20and\%20Advice\%20-\%202014-15\%209-3-14.pdf

Coles P, Cawley J, Levine PB, Niederle M, Roth AE, Siegfried JJ. The Job Market for New Economists: A Market Design Perspective. Journal of Economic Perspectives. 2010; 24(4):187-206.

Cook C, Heath F, Thompson RL. A Meta-Analysis of Response Rates in Web- or Internet-Based Surveys. Educational and Psychological Measurement. 2000; 60:821-836.

CPI Detailed Report Data for July 2014. U.S Bureau of Labor Statistics; Table 24http:// www.bls.gov/cpi/cpid1407.pdf [Accessed September 26, 2014]

Deck, KA.; Jebaraj, MJ.; Curington, WP. Survey of the Labor Market for New Ph D Hires in Economics 2011-12. Center for Business and Economic Research and Department of Economics, University of Arkansas Sam M. Walton College of Business; 2011. http://cber.uark.edu/ 2011-12_New_PhD_Labor_Market_Survey_Report.pdf

Duncan K, Yandell D, Kokila D. Job Search Strategies and Outcomes for Academic Economists: A Middle-Market View. Eastern Economic Journal. 2000; 26(3):345-361.

Ehrenberg RG. Prospects in the Academic Labor Market for Economists. Journal of Economic Perspectives. 2004; 18(2):227-238.

Hilmer MJ, Hilmer CE. Dissertation Advisors and Initial Placements for Economics PhD Recipients. Applied Economics Letters. 2007; 14(4-6):311-314.

Holmes J, Colander D. The Hiring of an Economist: A Case Study. The American Economist. 2007; 51(1):54-62.

List JA. Interview Scheduling Strategies of New Ph.D. Economists. Journal of Economic Education. 2000; 31(2):191-201.

National Science Foundation. Survey of Doctorate Recipients, 2013. 2014. http://ncsesdata.nsf.gov/ doctoratework/2013/html/SDR2013_DST1.html

Population Reference Bureau. 2008 World Population Data Sheet. Washington, D.C: 2008.

Siegfried JJ, Stock WA. The Labor Market for New Ph.D. Economists. Journal of Economic Perspectives. 1999; 13(3):115-134.

Siegfried JJ, Stock WA. The Market for New Ph.D. Economists in 2002. American Economic Review. 2004; 94(2):272-285.

Stock WA, Alston RM. Effect of Graduate-Program Rank on Success in the Job Mark. Journal of Economic Education. 2000; 31(4):4.

Stock WA, Alston RM, Milkman M. The Academic Labor Market for Economists: 1995-96. Atlantic Economic Journal. 2000; 28(2):164-185.

JEcon Educ. Author manuscript; available in PMC 2016 September 09. 
Stock WA, Siegfried JJ. So You Want to Earn a Ph.D. in Economics: How Much Do You Think You'll Make? Economic Inquiry. 39(2):320-335.

U.S. News and World Report. [Accessed August 2010] Best Graduate Schools, Economics Rankings. 2009. http://grad-schools.usnews.rankingsandreviews.com/best-graduate-schools/top-humanitiesschools/economics-rankings 
Table 1

Means of Background Variables

\begin{tabular}{|c|c|c|c|c|}
\hline & \multicolumn{2}{|c|}{ CV Sample } & \multicolumn{2}{|c|}{ Survey Sample } \\
\hline & Mean & Standard error & Mean & Standard error \\
\hline Female & 0.321 & 0.009 & 0.313 & 0.017 \\
\hline \multicolumn{5}{|l|}{ Undergraduate location } \\
\hline US & 0.356 & 0.010 & 0.370 & 0.017 \\
\hline Asia & 0.335 & 0.009 & 0.319 & 0.019 \\
\hline Other & 0.309 & 0.009 & 0.311 & 0.017 \\
\hline $\mathrm{PhD}$ program in US & 0.913 & 0.006 & 0.907 & 0.012 \\
\hline $\mathrm{PhD}$ program in economics & 0.909 & 0.006 & 0.916 & 0.011 \\
\hline \multicolumn{5}{|l|}{ Journal publications } \\
\hline 0 & 0.727 & 0.009 & 0.727 & 0.016 \\
\hline 1 & 0.161 & 0.007 & 0.159 & 0.013 \\
\hline 2 & 0.062 & 0.005 & 0.064 & 0.009 \\
\hline 3 or more & 0.049 & 0.004 & 0.050 & 0.008 \\
\hline Courses as teaching assistant & 3.813 & 0.048 & 3.943 & 0.098 \\
\hline Courses as primary instructor & 1.346 & 0.030 & 1.372 & 0.058 \\
\hline \multicolumn{5}{|l|}{ Rank of PhD program } \\
\hline $1-10$ & 0.288 & 0.009 & 0.292 & 0.017 \\
\hline $11-20$ & 0.134 & 0.007 & 0.135 & 0.011 \\
\hline $21-30$ & 0.123 & 0.007 & 0.115 & 0.011 \\
\hline $31-40$ & 0.091 & 0.006 & 0.086 & 0.011 \\
\hline $41-50$ & 0.101 & 0.006 & 0.100 & 0.011 \\
\hline Unranked & 0.263 & 0.009 & 0.273 & 0.017 \\
\hline \multicolumn{5}{|l|}{$\mathrm{PhD}$ fields } \\
\hline Applied econometrics & 0.208 & 0.008 & 0.193 & 0.015 \\
\hline Applied microeconomics & 0.214 & 0.008 & 0.212 & 0.015 \\
\hline Behavioral economics & 0.054 & 0.005 & 0.053 & 0.008 \\
\hline Development economics & 0.187 & 0.008 & 0.182 & 0.014 \\
\hline Econometrics & 0.171 & 0.008 & 0.161 & 0.014 \\
\hline Environmental economics & 0.059 & 0.005 & 0.058 & 0.008 \\
\hline Financial economics & 0.163 & 0.007 & 0.172 & 0.016 \\
\hline Game theory & 0.080 & 0.005 & 0.085 & 0.010 \\
\hline Health economics & 0.088 & 0.006 & 0.069 & 0.009 \\
\hline Industrial organization & 0.221 & 0.008 & 0.231 & 0.016 \\
\hline International economics & 0.090 & 0.006 & 0.099 & 0.012 \\
\hline International finance & 0.058 & 0.005 & 0.063 & 0.010 \\
\hline International trade & 0.062 & 0.005 & 0.071 & 0.010 \\
\hline Labor economics & 0.230 & 0.008 & 0.237 & 0.015 \\
\hline Macroeconomics & 0.231 & 0.008 & 0.227 & 0.016 \\
\hline Microeconomic theory & 0.086 & 0.006 & 0.096 & 0.011 \\
\hline
\end{tabular}

JEcon Educ. Author manuscript; available in PMC 2016 September 09. 


\begin{tabular}{lcccc}
\hline & \multicolumn{2}{c}{ CV Sample } & \multicolumn{2}{c}{ Survey Sample } \\
\hline & Mean & Standard error & Mean & Standard error \\
\hline Microeconomics & 0.059 & 0.005 & 0.051 & 0.008 \\
Monetary economics & 0.069 & 0.005 & 0.070 & 0.010 \\
Political economy & 0.073 & 0.005 & 0.074 & 0.009 \\
Public economics & 0.167 & 0.007 & 0.168 & 0.013 \\
Observations & \multicolumn{2}{c}{2506} & \multicolumn{2}{c}{850} \\
\hline
\end{tabular}

Notes: Column 1 contains statistics for the full sample of individuals for whom we have background data. Column 2 is restricted to respondents who provided information about all stages of the job markets and had non-missing values for each of the variables included in this table. Results weighted using post-market survey weights. Courses as teaching assistant is top-coded at 10 . Courses as primary instructor is top-coded at 5 . Job candidates may have more than one field; the typical candidate in our data has two fields. Fields excluded from table ( $<5 \%$ of sample):

computational economics, economic theory, economic history, economics of education, experimental economics, international macroeconomics, law and economics, and urban economics. 


\section{Table 2}

\section{Preferred job type}

\begin{tabular}{lcc}
\hline & Mean & Standard error \\
\hline Assistant professor at four-year college & 0.081 & 0.008 \\
Assistant professor at university & 0.719 & 0.013 \\
Researcher at NGQO & 0.111 & 0.009 \\
Researcher in business or industry & 0.068 & 0.008 \\
Postdoctoral fellow & 0.020 & 0.004 \\
Observations & \multicolumn{2}{c}{1333}
\end{tabular}

Notes: Table pools observations from pre-market surveys from the 2007-10 job markets and uses pre-market weights. "NGQO" stands for "nonprofit, government, or quasi-governmental organization." 
Table 3

Expected prestige relative to others in PhD-granting department

\begin{tabular}{lccc}
\hline & Mean & Standard error & Proportion at this decile or better \\
\hline 1st decile (most impressive) & 0.173 & 0.018 & 0.17 \\
2nd decile & 0.224 & 0.019 & 0.40 \\
3rd decile & 0.221 & 0.019 & 0.62 \\
4th decile & 0.105 & 0.015 & 0.72 \\
5th decile & 0.113 & 0.015 & 0.84 \\
6th decile & 0.046 & 0.010 & 0.88 \\
7th decile & 0.040 & 0.009 & 0.92 \\
8th decile & 0.028 & 0.007 & 0.95 \\
9th decile & 0.019 & 0.007 & 0.97 \\
10th decile & 0.032 & 0.008 & 1.00 \\
Observations & & 495 &
\end{tabular}

Notes: Results from 2009-10 pre-market survey only. Weighted using pre-market weights. 
Table 4

Mean number and success rates by job market stage

\begin{tabular}{lcccc}
\hline & Applications & Interviews & Fly-outs & Job offers \\
\hline Number & $107.0(2.3)$ & $16.8(0.4)$ & $5.7(0.2)$ & $2.9(0.1)$ \\
Observations $(N)$ & 905 & 905 & 905 & 905 \\
& Applications & Interviews & Fly-outs & Job offers \\
\hline Proportion resulting in interview & $0.194(0.006)$ & & & \\
Proportion resulting in fly-out & $0.076(0.004)$ & $0.366(0.009)$ & & \\
Proportion resulting in job offer & $0.040(0.002)$ & $0.200(0.006)$ & $0.573(0.011)$ & \\
Observations & 904 & 898 & 863 &
\end{tabular}

Notes: Standard errors in parentheses. Mean number applications, interviews, fly-outs and job offers are estimated for respondents who provided information about outcomes at all four stages. Mean success rates are estimated for respondents who provided information about outcomes at all four stages and had at least one choice at the stage for which the success rate is calculated. Estimates use post-market survey weights. Sample size is larger than survey sample column of table 1 because no additional covariates are included here. 
Table 5

Predictors of Percent Yield by Stage of the Market

\begin{tabular}{|c|c|c|c|}
\hline & Interviews per Application & Fly-outs per Interview & Job offers per Fly-out \\
\hline Female & $0.344(1.162)$ & $3.028(1.697)$ & $-3.511(2.357)$ \\
\hline \multicolumn{4}{|l|}{ Undergraduate Location } \\
\hline Asia & $-1.878(1.579)$ & $-1.373(2.181)$ & $9.677^{* * *}(2.853)$ \\
\hline Other & $-2.136(1.184)$ & $2.081(1.864)$ & $3.926(2.573)$ \\
\hline $\mathrm{PhD}$ program in US & $2.622(2.844)$ & $-1.916(4.433)$ & $2.597(5.193)$ \\
\hline $\mathrm{PhD}$ program in economics & $-7.300 *(2.935)$ & $-6.718(3.764)$ & $-1.904(4.620)$ \\
\hline \multicolumn{4}{|l|}{ PhD Program Rank } \\
\hline 11 to 20 & $-2.303(1.416)$ & $-1.427(2.304)$ & $-1.633(2.775)$ \\
\hline 21 to 30 & $-4.399^{* *}(1.473)$ & $-9.701^{* * *}(2.447)$ & $-4.369(3.754)$ \\
\hline 31 to 40 & $-3.739(1.985)$ & $-9.830^{* * *}(2.697)$ & $8.155(4.302)$ \\
\hline 41 to 50 & $-7.405^{* * * *}(1.928)$ & $-4.667(2.994)$ & $8.696^{*}(3.978)$ \\
\hline Unranked & $-3.864(2.570)$ & $-4.882(2.559)$ & $3.1(4.127)$ \\
\hline \multicolumn{4}{|l|}{ Journal Publications } \\
\hline One & $1.547(1.167)$ & $-1.015(2.108)$ & $4.621(2.742)$ \\
\hline Two & $5.095(3.915)$ & $-0.332(3.293)$ & $-4.041(5.378)$ \\
\hline Three or more & $6.584^{*}(3.207)$ & $1.498(3.401)$ & $0.03(4.735)$ \\
\hline Courses as TA, topcoded at 10 & $-0.367(0.209)$ & $-0.65(0.337)$ & $-0.449(0.495)$ \\
\hline Courses as PI, topcoded at 5 & $-0.823(0.453)$ & $-0.332(0.636)$ & $1.315(0.850)$ \\
\hline Constant & $30.691^{* * * *}(3.968)$ & $52.651^{* * * *}(5.836)$ & $49.424^{* * * *}(7.593)$ \\
\hline R-squared & 0.17 & 0.122 & 0.093 \\
\hline Observations & 849 & 844 & 811 \\
\hline \multicolumn{4}{|c|}{$\begin{array}{l}\text { Notes: Results from OLS regressions. Dependent variables are percent ( } 0 \text { to } 100) \text { of: applications resulting in an interview invitation (column } 1) \text {, } \\
\text { interviews resulting in a fly-out invitation (column } 2 \text { ), and fly-outs resulting in a job offer (column } 3 \text { ). Excluded categories are: "Undergraduate } \\
\text { location: US," PhD program rank "1 to } 10 \text {," and "0" journal publications. All regressions also include indicator variables for } 28 \text { research fields as } \\
\text { additional controls; field coefficients can be seen in the appendix. Uses post-market weights. }\end{array}$} \\
\hline \multicolumn{4}{|l|}{ p $<.05$} \\
\hline \multicolumn{4}{|l|}{ * ${ }^{* *}<.01$} \\
\hline *** $\mathrm{p}<.001$ & & & \\
\hline
\end{tabular}


Table 6

Marginal return in job offers from an additional application, interview or fly-out

\begin{tabular}{lccc}
\hline & $(\mathbf{1})$ & $\mathbf{( 2 )}$ & $\mathbf{( 3 )}$ \\
\hline Explanatory variable of interest: & Applications & Interviews & Fly-outs \\
\hline X variable & $0.01327^{* * * *}(0.00251)$ & $0.20306^{* * * *}(0.01945)$ & $0.55425^{* * *}(0.03943)$ \\
X variable squared & $-0.00003^{* * * *}(0.00001)$ & $-0.00210^{* * *}(0.00049)$ & $-0.00933^{* * * *}(0.00261)$ \\
Mean of X variable & 109 & 17 & 5.8 \\
Marginal effect at mean & $0.007(0.001)$ & $0.132(0.006)$ & $0.446(0.015)$ \\
R-squared & 0.20 & 0.42 & 0.67 \\
Observations & 850 & 850 & 850
\end{tabular}

Notes: Results from OLS regressions. Dependent variable in all columns is number of job offers. All regressions include all variables from Table 1 as controls. See appendix for regression variable estimates excluded from this table. In column 1, the explanatory variable of interest ("X variable") is number of applications, in column 2 it is number of fly-outs, and in column 3 it is number of fly-outs. Squared terms are included for explanatory variables of interest in each regression. Uses post-market survey weights.

p $<.05$;

***

$\mathrm{p}<.01$

****

$\mathrm{p}<.001$ 


\section{Table 7}

\section{Characteristics of accepted jobs}

\begin{tabular}{lcc}
\hline Panel A: Accepted job type & Mean & Standard error \\
\hline Assistant professor at four-year college & 0.08 & 0.01 \\
Assistant professor at university & 0.62 & 0.02 \\
Researcher at NGQO & 0.19 & 0.01 \\
Researcher in business or industry & 0.07 & 0.01 \\
Postdoctoral fellow & 0.05 & 0.01 \\
\hline Panel B: Preference rank of accepted job type & Mean & Standard error \\
\hline 1st choice job type & 0.64 & 0.02 \\
2nd choice job type & 0.20 & 0.02 \\
3rd choice job type & 0.09 & 0.01 \\
4th choice job type & 0.04 & 0.01 \\
5th choice job type & 0.03 & 0.01 \\
\hline Panel C: Accepted jobs on the tenure track & Mean & Standard error \\
\hline All accepted jobs & 0.59 & 0.02 \\
Jobs at colleges, excluding postdocs & 0.74 & 0.05 \\
\hline
\end{tabular}

Notes: All estimates weighted. Panels A and C use post-market survey sample weights, while panel B uses sample weights based on response to both surveys. Observations used are: 935 (panel A); 708 (panel B); 941, 83 and 569 (panel C, top to bottom). 


\section{Table 8}

Satisfaction with accepted job

\begin{tabular}{lcc}
\hline & Mean rating & Standard error \\
\hline Overall & 4.79 & 0.05 \\
Intellectual fit & 4.74 & 0.05 \\
Social fit & 4.69 & 0.05 \\
Compensation & 4.62 & 0.05 \\
Workload / work-life balance & 4.80 & 0.04 \\
Observations & & 565
\end{tabular}

Notes: Table pools observations from 2007-09 post-market respondents and uses post-market survey weights. Respondents weighted their satisfaction on a six-point scale where 1 was "extremely dissatisfied," 2 was "very dissatisfied," 3 was "somewhat dissatisfied," 4 was "somewhat satisfied," 5 was "very satisfied," and 6 was "extremely satisfied." The 2007-08 survey asked about "salary," while the 2008-09 survey asked about "compensation." The 2007-08 survey asked about "work load," while the 2008-09 survey asked about work/life balance. 

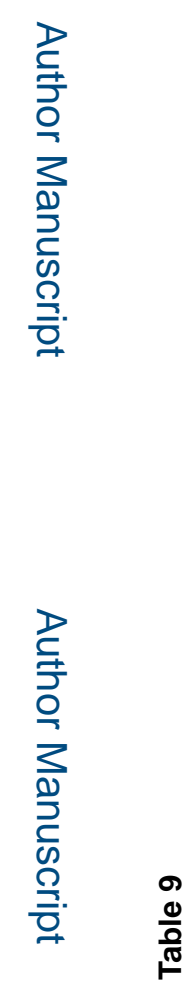

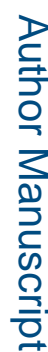

롬

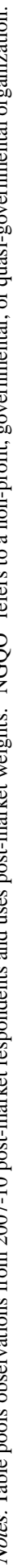


Table 10

Multinomial logistic regression: Predictors of accepted job type

\begin{tabular}{lcccc}
\hline & (1) College & (2) NGQO & (3) Business & (4) Postdoc \\
\hline Preferred job type: College & $5.04^{* *}(2.69)$ & $1.01(0.48)$ & $8.59^{*}(7.76)$ & $1.1(0.91)$ \\
Preferred job type: NGQO & $10.83^{* * *}(6.22)$ & $17.65^{* * *}(7.53)$ & $49.06^{* * *}(40.76)$ & $1.24(1.27)$ \\
Preferred job type: Business or industry & $9.59^{*}(8.93)$ & $6.95^{* *}(4.32)$ & $30.07^{* * *}(23.39)$ & $3.33(3.60)$ \\
Preferred job type: Postdoctoral fellowship & $16.23^{* *}(15.42)$ & $0.00^{* * *}(0.00)$ & $12.27(18.94)$ & $19.32^{*}(24.49)$ \\
Female & $0.82(0.34)$ & $1.29(0.43)$ & $1.93(1.20)$ & $1.67(1.03)$ \\
Undergraduate location: Asia & $1.16(0.56)$ & $0.51(0.18)$ & $1.27(1.04)$ & $0.31(0.31)$ \\
Undergraduate location: Other & $0.19^{*}(0.12)$ & $0.22^{* * *}(0.10)$ & $1.92(1.40)$ & $1.94(1.33)$ \\
PhD program in US & $1.37(1.11)$ & $0.36(0.28)$ & $2.18(2.90)$ & $0.04^{* *}(0.04)$ \\
PhD program in economics & $10.91(14.38)$ & $2.44(1.79)$ & $0.92(0.86)$ & $0.6(0.40)$ \\
PhD program rank: 11 to 20 & $0.42(0.33)$ & $1.44(0.60)$ & $0.32(0.25)$ & $7.73 * *(6.05)$ \\
PhD program rank: 21 to 30 & $1.35(0.86)$ & $3.09^{*}(1.58)$ & $1.37(1.03)$ & $1.41(1.36)$ \\
PhD program rank: 31 to 40 & $1.67(1.10)$ & $1.91(1.06)$ & $0.68(0.89)$ & $20.99^{* * *}(16.13)$ \\
PhD program rank: 41 to 50 & $1.11(0.90)$ & $2.43(1.32)$ & $3.05(2.39)$ & $5.3(5.04)$ \\
PhD program rank: Unranked & $2.64(1.60)$ & $1.57(0.94)$ & $2.05(1.47)$ & $1.77(1.89)$ \\
One journal publication & $0.98(0.51)$ & $0.59(0.25)$ & $0.48(0.44)$ & $1.77(1.07)$ \\
Two journal publications & $1.5(1.10)$ & $0.77(0.39)$ & $0.17(0.18)$ & $0.22(0.23)$ \\
Three or more journal publications & $0.31(0.36)$ & $0.56(0.34)$ & $0.67(1.26)$ & $1.13(1.00)$ \\
Courses as TA, topcoded at 10 & $0.98(0.08)$ & $1.16^{*}(0.07)$ & $1.31^{*}(0.14)$ & $0.99(0.11)$ \\
Courses as PI, topcoded at 5 & $1.47^{* *}(0.20)$ & $0.96(0.10)$ & $0.71(0.14)$ & $1.25(0.19)$
\end{tabular}

Notes: Regression uses 661 observations. Base outcome category is "Assistant professor at university." Relative risk ratios are reported. Excluded categories are: "Undergraduate location: US," PhD program rank "1 to 10," and " 0 " journal publications. Regression also includes a constant and indicator variables for 28 research fields as additional controls; estimates for these variables can be seen in the appendix. Uses survey weights for response to both surveys. "NGQO" refers to a non-profit, governmental, or quasi-governmental organization.

*

$\mathrm{p}<.05$

*** $\mathrm{p}<.01$

**** $\mathrm{p}<.001$

JEcon Educ. Author manuscript; available in PMC 2016 September 09. 


\section{Table 11}

\section{Predictors of salary}

\begin{tabular}{|c|c|}
\hline & Salary \\
\hline Female & $-1.11(2.03)$ \\
\hline \multicolumn{2}{|l|}{ Undergraduate location } \\
\hline Asia & $-14.70^{* * *}(2.60)$ \\
\hline Other & $-5.84 *(2.47)$ \\
\hline $\mathrm{PhD}$ program in US & $2.03(4.05)$ \\
\hline $\mathrm{PhD}$ program in economics & $-24.85^{* * *}(4.92)$ \\
\hline \multicolumn{2}{|l|}{ PhD program rank } \\
\hline 11 to 20 & $-5.71(3.50)$ \\
\hline 21 to 30 & $-11.23^{* *}(3.53)$ \\
\hline 31 to 40 & $-20.07^{* * *}(3.74)$ \\
\hline 41 to 50 & $-18.21^{* * *}(3.59)$ \\
\hline Unranked & $-18.61^{* * *}(3.64)$ \\
\hline Courses as TA, topcoded at 10 & $0.33(0.40)$ \\
\hline Courses as PI, topcoded at 5 & $-0.22(0.74)$ \\
\hline \multicolumn{2}{|l|}{ Journal publications } \\
\hline One & $-0.51(2.74)$ \\
\hline Two & $2.43(3.23)$ \\
\hline Three or more & $-3.66(4.33)$ \\
\hline \multicolumn{2}{|l|}{ Accepted job type } \\
\hline Assistant professor at four-year college & $-8.99^{* *}(2.93)$ \\
\hline Researcher at NGQO & $0.94(2.21)$ \\
\hline Researcher in business or industry & $15.13^{* *}(4.73)$ \\
\hline Postdoctoral fellow & $-25.23^{* * *}(3.17)$ \\
\hline Job offers & $7.70^{* * * *}(1.27)$ \\
\hline$(\text { Job offers })^{2}$ & $-0.33^{*}(0.13)$ \\
\hline Constant & $111.39^{* * * *}(7.17)$ \\
\hline R-squared & 0.51 \\
\hline Observations & 804 \\
\hline
\end{tabular}

Notes: Results from OLS regression. Dependent variable is salary in thousands of 2010 dollars. Excluded categories are: "Undergraduate location: US," PhD program rank "1 to 10," and "0" journal publications. Regression also includes indicator variables for 28 research fields as additional controls; estimates for these variables can be seen in the appendix. Uses post-market survey weights. "NGQO" refers to a non-profit, governmental, or quasi-governmental organization.

*

$\mathrm{p}<.05$;

*** $\mathrm{p}<.01$;

**** $\mathrm{p}<.001$

JEcon Educ. Author manuscript; available in PMC 2016 September 09. 
